\title{
Rare and Interesting Case of Eye Choriodal Melanoma Presenting as a Congestive Glaucoma in a 55 Years Male Patient
}

\author{
Gowhar Ahmad* \\ Department of ophthalmology, University of Jammu and Kashmir, India
}

Submission: January 28, 2017; Published: August 07, 2017

*Corresponding author: Gowhar Ahmad, Department of ophthalmology, University of Jammu and Kashmir, India, Tel: 9419009850/9622983444; Email: gowhar.ahmad1948@gmail.com

\begin{abstract}
55 years male patient presented as a case of a glaucoma in 2011 at ER ophthalmological dept of medical hospital Srinagar Kashmir, he presented with severe pain marked redness of left eye and marked loss of vision on exam he had sever ciliary congestin corneal odema very shallow a chamber and dilated pupil no clear view of fundus and IOP of more than $550 \mathrm{~mm} \mathrm{Hg}$. He was put on emergency medication of a c glaucoma in form of topical LUPITISS eye drops one drop l eye od 2 britiblu eye drops i drop L eye bd 3 osmotic diuretic 20 percent mannitol $250 \mathrm{cc}$ IV $4500 \mathrm{mf}$ of injection diamox I we even with this medication pt dod not respond even after more than 12 hours of this medication he was advised admission which he refused however no a aor B-scan ultrasound was done pt after couple of days sought second ophthalmic consultation this time the con ophthalmologist performed B-scan ultrasound and picked up a solid retinal detachment of 1 eye to confirm melanoma.ch he was referred for MRI scan of orbits and brain unfortunately for patient and treating ophthalmologist the report of scan was very unsatisfactory the radiologist gave a very unsatisfactory report that pt has pan ophthalmitis l eye however ophthalmologist requested him that this is a case of CD melonoma [1], and it has to be confirmed by MRI in this process p both pt and got confused and patient left the treatment he was unfortunately going from one oph to other as a painful blind eye for two years key words melanoma.ch is the commonest tumor it can be benign or malignant LUPITISS $\mathrm{t}$ is prostaglandin analogue and $\mathrm{t}$ stands for temilola beta blocker beta blocker 3 britiblu is brimolol 3 mannitol is osmotic duretic 4 diamox is carbonic anhydrase inhibitor od means one dop once a day $5 \mathrm{bd}$ is one drop twice a day glaucoma is a v=condition where i o gets raised in eye pathogenesis of IOP aqueous is produced by ciliary process of ciary epethelium im post chamber where [2], the aqueous nourishes lens then through pupil it comes in ant chamber and aqua nourishes cornea and then it is dained though angle of filtration through canal of schlem and finally aqueous comes in aqua veins so any condition which causes obstruction in drainage of aqueous will result in rise of IOP which is called glaucoma classification of glaucoma cong glaucoma occurs during intra uterine life 2 infantile glaucoma if from birth to 3 years 3 juvenile off 3 years to 17 years 2 primary glaucoma open and closed angle $3 \mathrm{sec}$ glaucoma which occurs sec to any intraocular disease 4 ocular hypertension sec to systematic tension dx of cong glaucoma also called buphthalmos big eye ball a large cornea we do under anesthesia in these neonates and measure [3], IOP and measure corneal diameter treatment modalities which $r$ surgical have been
\end{abstract}

I. Goniotomy

II. Goniopexy

III.Trabeculotomy

IV.Sinostomy

\section{Case Report}

In open angle glaucoma there is no pain moderate rise of IOP causes headache there are 3 features

a. Fundus changes

b. Changes in visual fields
Fundus causing glaucomatous cupping and even optic atrophy most the times pts of open angle glaucoma are diagnosed late due to lack of pain and pt may come when pt already [4], had glaucomatous cupping and optic atrophy that's why we are doing glaucoma screening after 40 years of age where we do 
routine measuring of IOP refraction and fundus examination in this screening we are able t pick up cases of open angle glaucoma treatment is medical and surgical first [5], we put it on medical therapy and if it doesn't not respond to it or it not coming for regular ophthalmic evaluation or pt belongs to fat of place lack of ophthalmic advice one should do surgery the surgical modalities are 1 trabeculectomy advantages of this procedure

1. It is cosmetically better

2. It can be repeated

3. It is a physiologically better operation

4. It communicates the ant $\mathrm{c}$ with canal of schlem by splitting the trabecular mesh work

Nowadays, we have better options of lased and operation of laser choice is an argon laser trabeculoplasty closed angle glaucoma comes very early due [6], to severe pain redness and marked loss of vision in most of the these case they respond to anti glaucoma medication after the eye settled down we do laser iridotomy even in normal eye of these pts we do polylectic laser iridotomy then we have ocular hypertension due to systemic hypertension key is control of $b$ p ten we have a miscellaneous group of glaucoma 1 neo vascularisation glaucoma due to $\mathrm{c}$ are $\mathrm{c}$ occlusion it is said to subside in 3 months last 1 by least we have absolute glaucoma pt has painful blind eye treatment modalities.

\section{a) Cyclodiathermy \\ b) Cyclo croprexy}

Sometimes due to severe pain we may inject retrobulbar injection of xylocaine or alcohal to revealve pain sometimes one may have to enuck leation if all measures fail introduction ch melanoma is the most common primary malignan intraocular tumor and the second most common type of primary malignant melanoma in the body it most often whites of northern European descent essential update early treatment may prevent metastatic deaths in patients with melanoma.ch in a prospective cohort study of 3072 patients with melanoma. ch researchers we found for some pts early treatment rather than watching and waiting might better prevent metastatic deaths signs and symptoms melanoma.ch remain asymptomatic for prolonged period of time may be found incidentally during ophthalmoscope in general the more the their origin the longer the delay of any symptoms melanoma.ch present with following symptoms:
a. Blured vision
b. Paracentral scotoma
c. Progressive and painless visual loss
d. Floaters
e. Sever ocular pain

f. Weight loss marked fatigue cough or change in bowel or bladder suggests primary non ocular malignancy with melanoma.

ophthalmological examination may reveal following

A. Small melanoma.ch typically takes the form of a nodular dome shaped and well circumscribed mass under the retinal pigment epethelium

B. Melanoma.ch grow they adopt more irregular configurations

C. Diffuse melanoma.ch characterized by growth throughout the choroid with minimal elevation are more difficult to diagnose and often cause significant exudative redetachment

D. Melanoma.ch may have variable coloration some are more pigmented and others are less

E. If tumor is light colored its abnormal vascularisation usually can be seen ohthalmoscopicaly

\section{F. Overlying melanoma. ch}

There are usualy tet pig epethelial changes eg drusen $\mathrm{dx} 1$ liver enzyme are indicated in any pt with uveal melanoma is the most common site of melanoma.ch metastases so one has to do

a. Alkaline phosphates

b. Glutamic oxaloacetic trans aminase

c. Lactase dehyrogenase

Gamma glutamyl transpeptidase a scan and B-scan ultrasound MRI scan ct scan $\mathrm{f} f$ angoigraphy can help point toits dx 2 small ch melanomas may show floresene angigrahkic changes similar to choriodal nevi 3 large melanomas may show patchy pattern of early hypoflourence and hyper flourescence followed by late intense staining simultaneous flourescence of retinal [7-8], and ch circulation within is fiarly distintive of melanomas.ch management

I. Observation may be acceptable for post uveal tumors not well established in particular tumors of less than

II. To $2.5 \mathrm{~mm}$ and $10 \mathrm{~mm}$ in diameter can be observer until growth is documented

III. Plaque brachy therapy is a widely accepted alternative to enucleation medium sised post uveal melanomas less than $10 \mathrm{~mm}$

IV. External beam irradiation with protons and helium ions

V. Pp vasectomy

VI. Block excision

VII. Laser photocoagulation

VIII. Orbital exenteration in extreme cases. 


\section{Introduction}

The above mentioned pt b was seen by me in 2013 his all investigations $\mathrm{l} f \mathrm{t} \mathrm{c}$ bc $\mathrm{k} \mathrm{f} \mathrm{t}$ lipid profile $\mathrm{f} \mathrm{b} \mathrm{s}$ were within normal limits ultrasound abdomen normal no evidence of any metastases i requested for MRI scan of orbits and brain it was very satisfactory showing that optic nerve optic tract Chiasm a basal ganglia pit gland thalmoid brain ventricles and cerebral hemispheres all were normal discussion we have aired mentioned that scleral cavity can be

1. Antto lens so it will cause visual impairment

2. Involve vitrous causind floaters

3. Involve angle of filtration and present and a c glaucoma as was seen in our case.

\section{Discussion}

So after all above mentioned investigations under gowhar ahamed I removed whole cornea lens vitrous choriod and retina [9-11], so we were left with intact intra scleral cavity optic nerve and all ocular muscles i stitched ant and pst lips of sclera with 6 zero vicryl kept a drain in intra scleral cavity which was removed after 24 hours later i put a confirmer to give shape to orbit for 15 days after removal of confirmer i fitted a well matching and fitting prosthesis the removed tissues were sent for histopathological examination did not show any evidence of malignancy 3 years [12-15], have passed all repeat tests od blood ultra sonography b abdomen are normal.

\section{Conclusion}

So any pt $\mathrm{f}$ ac c glaucoma if does not respond to treatment please do a or b scan ultrasound to pick up solid ret det and rule out $\mathrm{m}$ melanoma.ch by MRI review of literature 1 vertex varies can present as Uveal melanoma however it is a benign condition and temporary 2 in dept of ophthalmology manchester a pt came with a c glaucoma vision in normal eye unaided was 6,18 have did not respond to treatment MRI showed melanoma.ch so Enucleation was done 2 in Saudi medical lornal and cairio institute of ophthalmology and nophthalmology one pt came with BSEC glaucoma with imp of 56mmhg pt did not respond to treatment MRI was done it revealed melanoma.ch so Enucleation was done.

\section{References}

1. Meyer S (1977) Treatment of malignant melanomas of choroid by photocoagulation tans ophthamol soc, UK 97: 416-420.

2. Samuel P, Marvin R (1980) Radiotherapy of choroidal melanoma with iodinw 125 ophthalmology 87(6): 582-590.

3. Gholam AP, Dodich NA (1979) Full-Thickness eye ball resection of choroidal neo-plasms. Ophthalmology 86: 1024-1036.

4. Jerry AS, James JA, Luther WB, John L (1982) Cobalt plaque theapy of post uveal melanomas. ophthalmology 89(10): 1201-1207.

5. Devron HC, William S, Joseph RC, Jeanne MQ Alexander RI, et al. (1983) Helium ion thearpy for choroidal melanomas. Ophthalmology 90(10): $1219-1225$

6. David TT, Jonathan JD, Thomas AW (1984) Hematoporphyrin photoradiation therapy for intraocular and orbital malignant melanoma. Arch ophthalmol 102(6): 833-836.

7. Evangelos SG, Johanna S, Michael G, Lynn V, John M, et al. (1985) Current Results of Proton Beam Irradiation of Uveal Melanomas. ophthalmology 1992: 284-291.

8. Foester MH, Bornfield NW (1984) Die behandlung von malignen melanomen deruvea unit 106 ruthenium- applikatoren. Bericht uber S 1985: 490-494.

9. Cappin JM (1973) Malignant melanoma and rubeosis iridis. Histopathological and statistical study. Br J Ophthalmol 57(11): 815824 .

10. Char DH, Castro JR, Quivey JM, Chen GT, Lyman JT, et al. (1980) Helium ion charged particle therapy for choroidal melanoma 87(6): 565-570.

11. Lyman JT, Howard J (1977) Dosimetry and instrumentation for helium and heavy ions. Int J Radiat Oncol Biol Phys 3: 81-85.

12. Goitein M, Miller T (1983) Planning proton therapy of the eye. Med PhyS 10(3): 275-283.

13. Hanna SL, Lemmi MA, Langston JW, Fontanesi J, Brooks HL, et al. (1990) Treatment of choroidal melanoma: MR imaging in the assessment of radioactive plaque position. Radiology 176(3): 851-853.

14. Bond JB, Haik BG, Mihara F, Gupta KL (1991) Magnetic resonance imaging of choroidal melanoma with and without gadolinium contrast enhancement. Ophthalmology 98(4): 459-466.

15. Kivelä T, Summanen P (1997) Retinoinvasive malignant melanoma of the uvea. Br J Ophthalmol 81(8): 691-697.

Your next submission with Juniper Publishers will reach you the below assets

- Quality Editorial service

- Swift Peer Review

- Reprints availability

- E-prints Service

- Manuscript Podcast for convenient understanding

- Global attainment for your research

- Manuscript accessibility in different formats

( Pdf, E-pub, Full Text, Audio)

- Unceasing customer service

Track the below URL for one-step submission https://juniperpublishers.com/online-submission.php 